\title{
Pombos: distribuição dos problemas registrados no Distrito Federal, Brasil*
}

\section{Pigeons: distribution of problems registered in the Federal District, Brasil}

\author{
Lívia Thayane da Silva Cunha, ${ }^{* *}$ Ligia Cantarino, ${ }^{* * *}$ Paulo Vinicius Neves Fernandes, ${ }^{* *}$ Frederico Tôrres Braz, ${ }^{* * *}$ \\ Debora Marcolino Silva**
}

\begin{abstract}
Resumo
Os animais sinantrópicos, dentre eles os pombos, constituem uma fonte de incômodo e problemas de saúde pública no meio urbano. Encontram-se dispersos por todo o território brasileiro. Devido a sua domesticação e distribuição no ambiente, os pombosdomésticos (Columba livia) levam a queixas por nidificações, infestação por ácaros e notificações de doenças humanas. Diante disto, foi efetuado levantamento documental dos registros de reclamações feitas pela população à Diretoria de Vigilância Ambiental (DIVAL) do Distrito Federal, no período de 2014 a 2016, com o objetivo de mapear as áreas com vulnerabilidade e propor soluções para reduzir a presença desses animais sinantrópicos e a incidência de agravos. Alimento, abrigo e água são elementos essenciais para a aproximação e permanência com o homem. A distribuição das reclamações apresenta expansão principalmente na zona urbana, e outras onde nunca houve notificação, sendo que o número de notificações para estabelecimentos privados se mostrou maior que para públicos. O controle populacional desses animais é complexo e os serviços de controle encontram dificuldades em suas atividades.
\end{abstract}

Palavras-chave: pombos, vigilância em saúde pública, Distrito Federal.

\begin{abstract}
Synanthropic animals, including pigeons, are a source of nuisance and public health problems in the urban environment. Dispersed throughout the Brazilian territory due to their domestication and distribution, domestic pigeons (Columba livia) of the Columbiformes class lead to complaints of mite infestation, nesting and notification of human diseases. In view of this, a documentary survey of the records of complaints made by the population to the Environmental Surveillance Directorate (DIVAL) of the Federal District was carried out, in the period from 2014 to 2016, in order to map the vulnerable areas and propose solutions to reduce the presence of these synanthropic animals and the incidence of injuries. The distribution of complaints is expanding mainly in the urban area, and others where there was never any notification, with the number of notifications for private establishments being higher than for public ones. The population control of these animals is complex and the control services face difficulties in their activities.
\end{abstract}

Keywords: pigeons, public health surveillance, Federal District.

\section{Introdução}

Dentre os animais sinantrópicos, o pombo doméstico (Columba livia domestica), constitui um transtorno de ordem sanitária em áreas urbanizadas. Os pombos domésticos são aves mansas originadas no Mediterrâneo (Europa, norte da África, Oriente Médio e Ásia) tendo sido domesticadas e espalhadas pelo mundo (BENCKE, 2007). Pertencem à Ordem Columbiformes e à Família Columbidae. Trazidos pela família real portuguesa, encontram-se dispersos pelo território brasileiro devido à disponibilidade de alimentos, locais de nidificação e a ausências de predadores (NUNES, 2003; MONTENEGRO NETO e NUNES, 1998).

A elevada quantidade de pombos traz prejuízos para a população humana e danos de diversas ordens, seja pelas sujidades devidas ao acúmulo de fezes em monumentos, prédios, vias públicas, veículos, perda de produtos agrícolas (MEZA, 2009), seja por transmissão de doenças ao homem. Dentre as doenças zoonóticas dentre as quais se destacam a criptococose, a clamidiose, a salmonelose e a histoplasmose (NUNES, 2003; BRASIL, 2016). Microrganismos patogênicos e parasitos associados aos excrementos dessas aves, podem ser transmitidos ao homem principalmente pela suspensão de partículas secas no ar que podem ser inaladas contendo além de sujeira, fezes ressecadas e agentes patogênicos (SCHULLER, 2005).

As regiões administrativas (RA) do Distrito Federal (DF), tanto em órgãos públicos ou residências, apresentam problemas ocasionados pela presença dos pombos como acúmulo de fezes, sujidades e ectoparasitas, além do poder de transmissão de zoonoses (SHULLER, 2005) - e dermatites por meio de contato com os pombos ou fezes (SANTOS, 2011).

\footnotetext{
${ }^{*}$ Recebido em 31de janeiro de 2021 e aceito em 22 de fevereiro de 2021.

${ }^{* *}$ Médico-Veterinário autônomo, Brasília-DF.

***Faculdade de Agronomia e Medicina Veterinária, Universidade de Brasília, Brasília-DF.

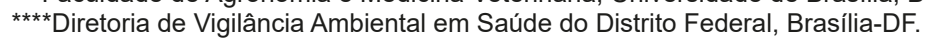


Sua fácil adaptação ao ambiente urbano se dá pela disponibilidade de elementos essenciais à sua existência. São estes a água, o abrigo e o alimento que contribuem para o perpetuar seu ciclo reprodutivo e fixação nas cidades (NUNES, 2003). Segundo Schuller (2005), após um ano, o bando de pombos pode ter duplicado o número de indivíduos, mesmo com baixa taxa de sobrevivência, que é de $43 \%$ para os filhotes que deixam os ninhos, e de $66 \%$ para os adultos. A maior quantidade de alimento disponível está relacionada à capacidade reprodutiva, e aumenta a postura de ovos que varia de 10 a 14 ovos por ano/ fêmea em um período médio de 4 a 6 anos.

O controle populacional de pombos é complexo e os resultados muitas vezes não são alcançados ou satisfatórios. As atividades desenvolvidas para esta finalidade são de incumbência dos serviços de controle de fauna sinantrópica e atendem ao disposto na Constituição Federal, além de legislações e normativas que visam aspectos de vigilância à saúde (NUNES, 2003; MOUTINHO et al, 2015; BRASIL, 2016). Considerando uma sociedade cujos hábitos atraem a presença desses animais, aliado ao conceito simbólico de paz, liberdade e ternura que os pombos carregam, pode se perceber o impacto do problema.

Para o controle dessa espécie sinantrópica é preciso além de quantificar formas de notificações usuais e sua característica predominante, identificar logradouros e regiões com maior número de reclamações, descrever a situação da região em números de abrigos, ninhos, disponibilidade de alimentos. no setor de animais sinantrópicos da Diretoria de Vigilância Ambiental (DIVAL) do Distrito Federal.

\section{Material e métodos}

O estudo descritivo foi realizado com base na análise documental dos registros das reclamações, da vigilância ambiental, acerca de problemas relativos à presença de pombos no Distrito Federal, de 2014 a 2016.

Os dados foram tabulados e trabalhados empregando-se o programa Excel® para cálculo da média, das frequências absolutas e relativa por Região Administrativa. Foi feita análise da relação entre a frequência de reclamações e as médias de temperatura, população e renda por região administrativa. Com ultilização do software de geoprocessamento Sistema de Informação Geográfica (SIG) Quantum GIS® (SHERMAN, 2015), os dados foram distribuídos espacialmente em mapa, com base na localização geográfica da reclamação do bairro e região administrativa.

O Distrito Federal (Latitude $15^{\circ} 46^{\prime} 47^{\prime \prime}$ S Longitude $47^{\circ} 55^{\prime} 47^{\prime \prime}$ O) apresenta área de $5.779,997 \mathrm{~km}^{2}$ e a população estimada para 2016 na ordem de 2.977.216 habitantes. Possui índice de desenvolvimento humano (IDHM) de 0,824, considerado elevado em comparação a outras regiões do país (IBGE, 2016). Está dividido em 31 regiões administrativas, apresentadas na Figura 1.

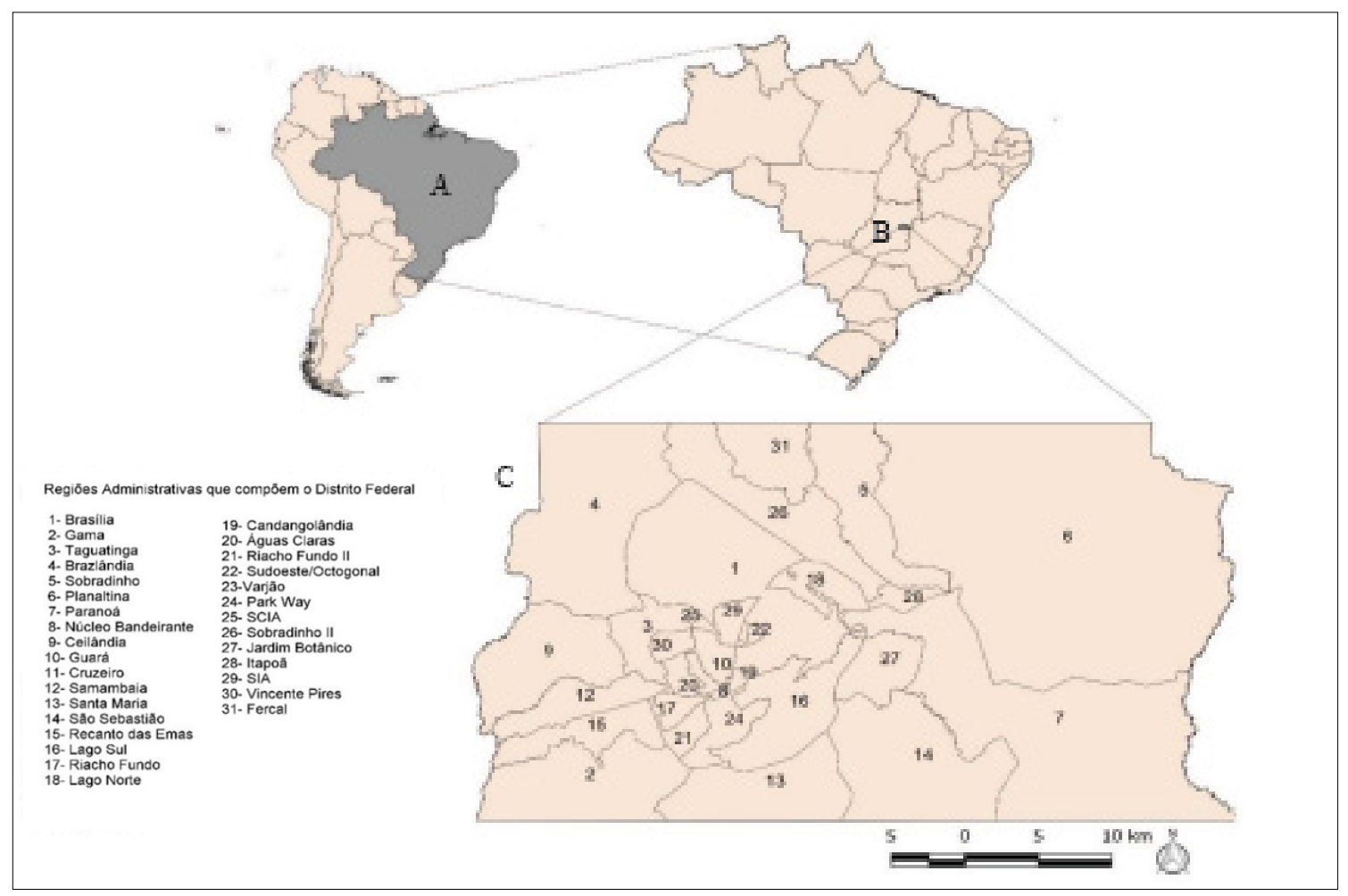

Figura 1: Regiões Administrativas do Distrito Federal. Legenda: Brasil (A); Distrito Federal (B); Regiões Administrativas (C).

O objetivo deste estudo foi descrever a distribuição espacial e temporal das reclamações acerca de pombos registradas
A DIVAL, unidade orgânica criada na década de 1960, está diretamente subordinada à Subsecretaria de Vigilância a 
Saúde (SVS), na Secretaria de Saúde do Governo do Distrito Federal. Tem por competência conhecer e detectar as mudanças nos fatores determinantes e condicionantes do meio ambiente que interferem na saúde humana, com a finalidade de recomendar e adotar as medidas de prevenção e controle dos fatores de riscos e das doenças ou agravos relacionados à variável ambiental (GDF, 2017; SANTOS, 2011).

Foi realizado levantamento junto à DIVAL dos documentos catalogados e registros das solicitações/reclamações sobre problemas relativos aos pombos domésticos. Foram considerados os dados das localidades como as características das RA, renda e população de habitantes.

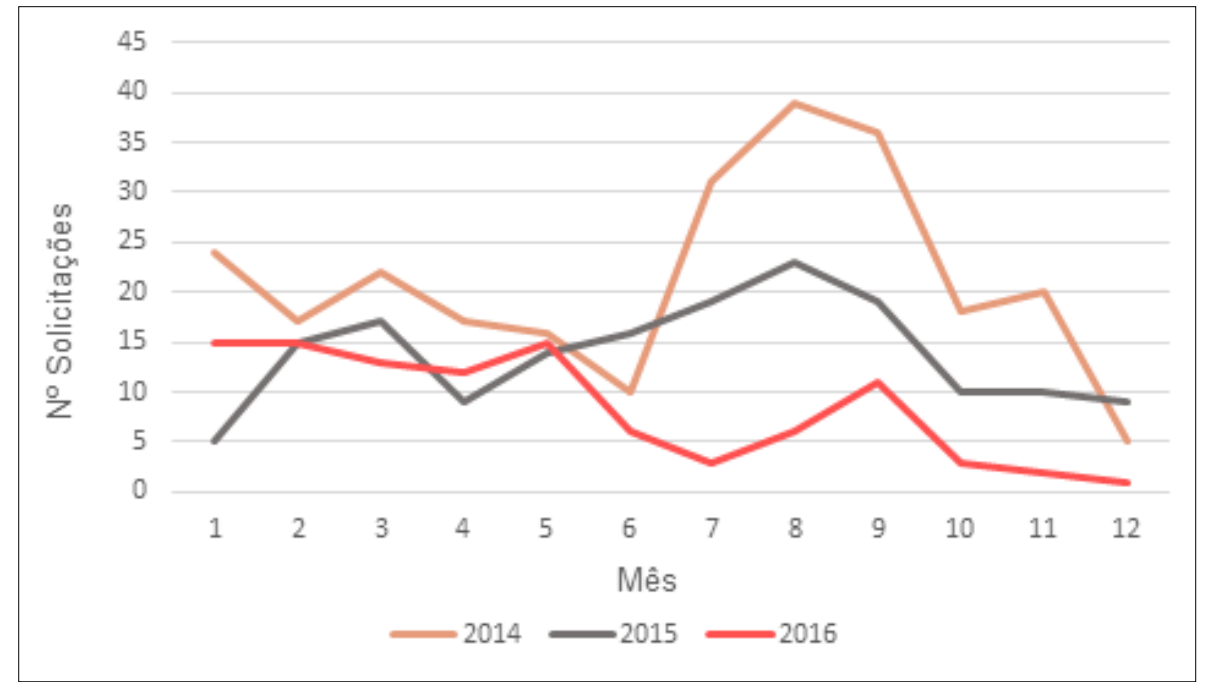

Figura 2: Registros mensais de solicitações/reclamações acerca de pombos no Distrito Federal no período de 2014-2016

\section{Resultado e discussão}

Um total de 535 solicitações e ou queixas acerca de agravos relativos a pombos, foram registradas du-rante os anos de 2014 a 2016, junto à Vigilância Ambiental. Tal fato aponta os hábitos e conceitos que a população da região agrega aos pombos domésticos. O ano de 2014 foi o que mais foi constado reclamações $(n=256)$ e 2016 foi o ano com menor registro de queixas (Figura 2). presença dos animais - foi verificada em $20 \%$ a presença dos mesmos fatores predisponentes.

Das 535 reclamações, o maior número ocorreu na RA Guará, com 50 solicitações, seguida pela RA Gama, com 48. As RA de Brasília, Samambaia e Taguatinga apresentaram 47 registros; em Ceilândia houve 46 queixas. A RA Jardim Botânico apresentou uma solicitação e a RA Fercal não apresentou nenhuma solicitação no período estudado (Figura 3).
Foi observada diminuição do número de solicitações/reclamações acerca de problemas relativos à presença de pombos ao longo do período, sendo o maior número - 255 - no ano de 2014 e o menor - 102 - em 2016. Em 2015 foram constatadas 166 reclamações. Observação semelhante à de Santos (2011), também no DF, que constatou uma regressão no número das solicitações/reclamações relativas a pombos no período de 2008 a 2010.

O maior registro de solicitações/ reclamações era de estabelecimentos privados e representaram $81 \%(436 / 535)$. Dentre os estabelecimentos privados, $60 \%$ (324) eram residências, nas quais em $33 \%$ (108/324) foi constatado algum fator predisponente para a presença de pombos como abrigos, ninhos, alimentos e ou local de pouso. Em estabelecimentos públicos (escolas, unidade de saúde, delegacias e outros) - mesmo considerando as formas arquitetônicas características das edificações do DF, que se constituem como agravante para a

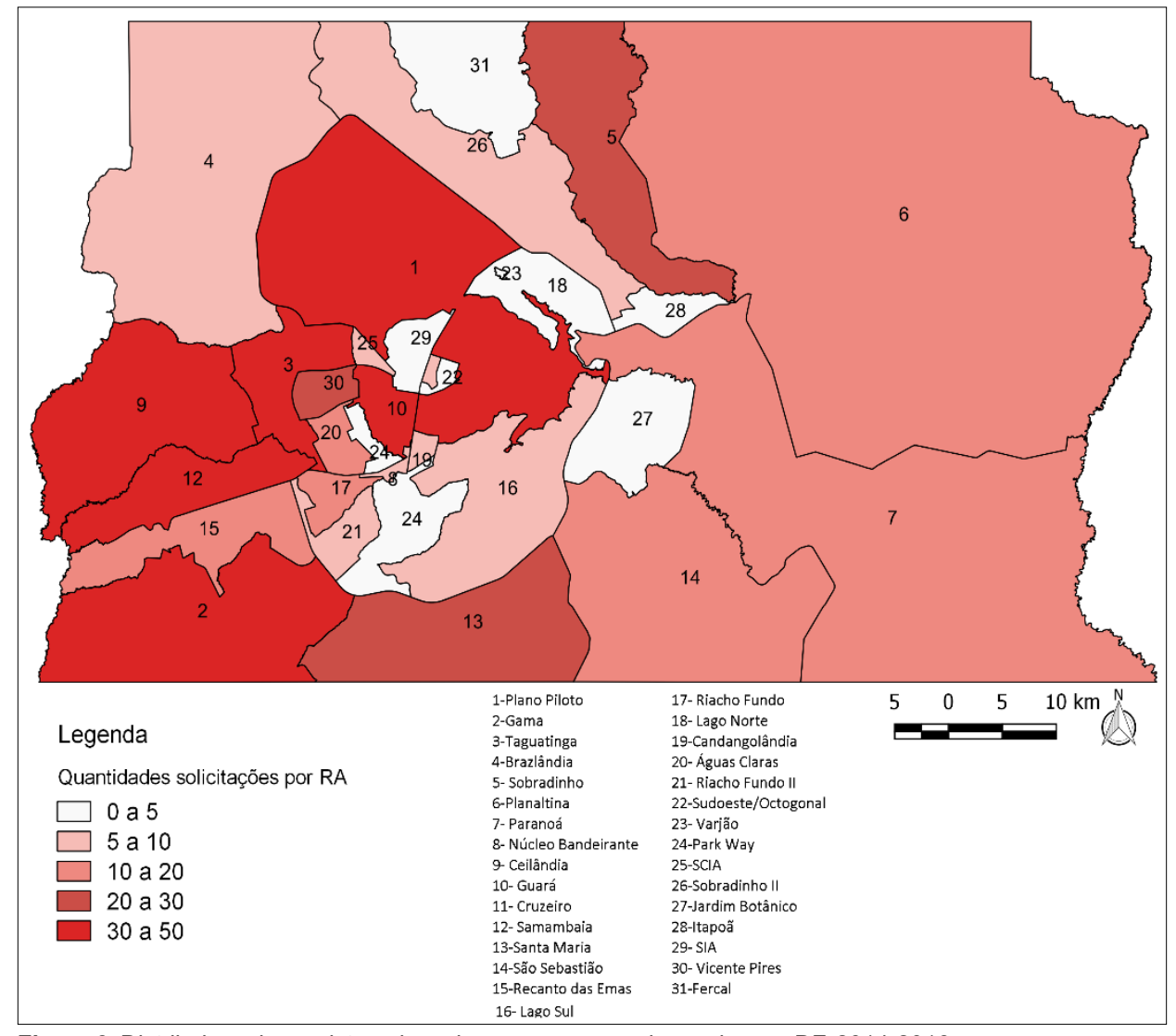

Figura 3: Distribuição dos registros de reclamações acerca de pombos no DF, 2014-2016 
A principal forma de reclamação, com $70 \%$ dos registros, se deu por telefone, totalizando 373 registros. Essa via de comunicação apresentou queda de registros ao longo dos anos, devido à ausência de linhas telefônicas nos núcleos de vigilância no ano de 2016, e foi reduzida a zero pela interrupção do serviço de telefonia na DIVAL, o que representa ruptura do canal de comunicação do órgão público de atendimento à população.

Os registros mensais das solicitações/reclamações ao longo dos três anos (Figuras 4 e 5) apontam uma possível sazonalidade, sendo em maior número nos meses de julho, agosto e setembro - com média de 17,6; 22,6; e 22 registros mensais, respectivamente, no período estudado. Esses meses se caracterizam pelo início das estações de inverno, em junho, e a primavera, em setembro, quando há um decréscimo do número de registros e, após, um aumento, com a chegada do verão (Figura 4).

Em centros urbanos é observada a reprodução dessas aves durante todo o ano, em condições favoráveis (NUNES, 2003), embora a estação de reprodução dos pombos varie do final do outono até o início do inverno (HAKKINEN et al, 1973).

Há estudos paquistaneses que registram que a densidade populacional de pombos em Islamabad foi mais elevada no inverno e outono. Já a densidade populacional de pombos verificada em Rawalpindi se apresentou mais elevada no verão e inverno (ALI et al., 2013). Haag-Wackernagel (1995) relatou que as mudanças sazonais não alteram a população e têm pouco efeito sobre a população de pombos em áreas urbanas; no entanto, os locais de pouso e nidificação se modificam com a mudança de acesso a comida e água.

A distribuição das reclamações no decorrer do ano, com predomínio nas estações de outono e inverno, foi relatada no trabalho de Moutinho e colaboradores (2015), no município de Niterói, no estado do Rio de Janeiro.

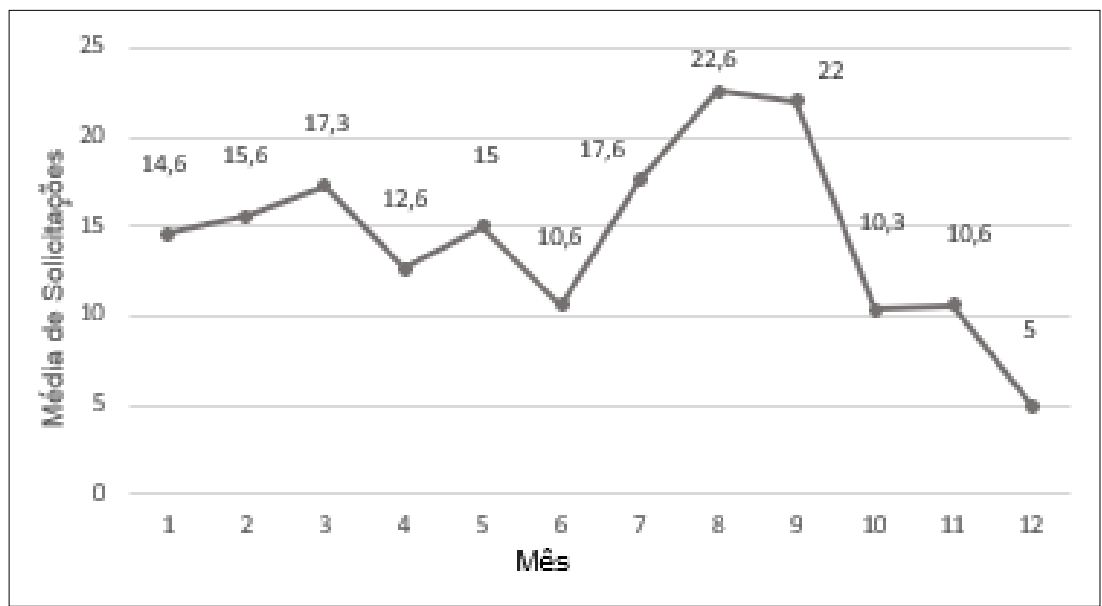

Figura 4: Média mensal dos registros das reclamações acerca de pombos no DF, 2014-2016
O aumento das reclamações durante o inverno pode estar associado ao possível aumento da densidade populacional das aves, e também ao fato de os pombos ficarem nos locais de nidificação e abrigos por mais por mais tempo (FERMAN et al., 2010).

No DF, o fato de os meses com maiores números de reclamações coincidirem com o inverno pode ter relação com o aumento populacional de pombos devido à época reprodutiva em estação anterior; ou pelo maior número de pombos em busca de alimentos naturais escassos ou abrigos pelas intempéries da estação, o que leva ao incômodo da presença mais constante dos animais, para a população.

O DF possui RA mais populosas como Ceilândia, Samambaia, Brasília, Taguatinga,

Ao verificar as médias mensais dos registros de reclamações e a temperatura média - máxima e mínima - do DF (CLIMATEMPO, 2017), foi observado que os meses com maior média de registros de reclamações não coincidem com os meses de menor temperatura média, referentes ao início do inverno e primavera (Figura 5).

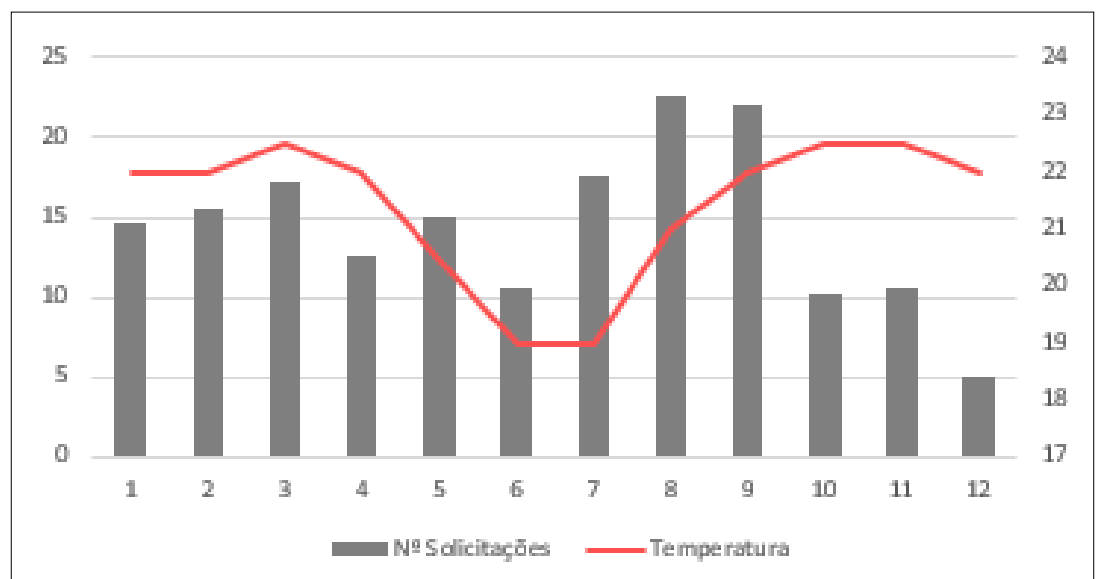

Figura 5: Média mensal de registros das reclamações acerca de pombos e temperatura máxima/ mínima no DF, 2014-2016
Planaltina e regiões menos populosas como Park Way, Candangolândia, Varjão, Fercal e SIA (IBGE, 2016). As RA mais populosas - Brasília, Taguatinga, Ceilândia e Samambaia - estão entre as regiões com maior registro de solicitações/ reclamações (Figura 6).

É consenso que o desenvolvimento humano decorre de interação das características do indivíduo com o ambiente (CHIARENTIN, et al., 2012) e a correlação entre a renda média e o nível de escolaridade é positiva (SALVATO, FERREIRA e DUARTE, 2010). As diferenças entre os indivíduos podem ser observadas quanto ao lugar que eles ocupam na hierarquia social e estão associadas às diferenças relacionadas às oportunidades educacionais, trajetórias ocupacionais, prestígio social, acesso aos bens e serviços, comportamento político e social etc. A observação dessas diferenças pode ser por meio de variáveis como os níveis de escolaridade ou de renda (ALVES e SOARES, 2009).

Ao se considerar os dados renda per capita da Pesquisa Distrital por Amostra de Domicílios 


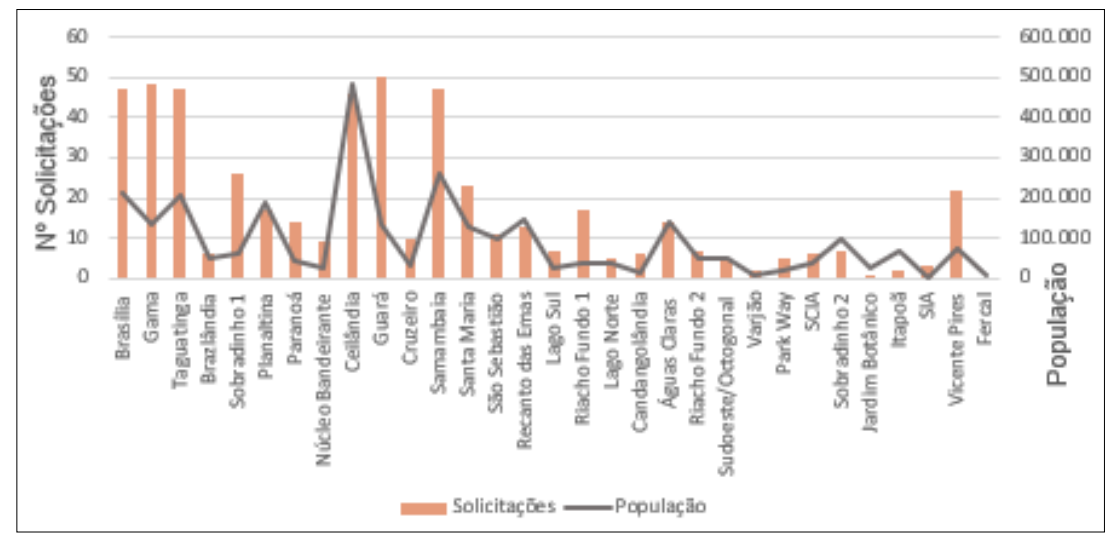

Figura 6: Distribuição dos registros de solicitações/reclamações acerca de pombos por população e RA, no DF, 2014-2016

(DISTRITO FEDERAL, 2015) como parâmetro e influência na quantidade de registros de solicitações/reclamações por RA, foi observado que a ocorrência de maior número de solicitações/ reclamações está distribuída, em ordem decrescente, no Grupo 1 - Alta Renda (acima de R\$ 10.000,00): Brasília; Grupo 2 Média/Alta Renda (entre R\$10.000,00 e R \$ 5.000,00): Guará e Taguatinga; Grupo 3 - Média/Baixa Renda (renda domiciliar entre $\mathrm{R} \$ 5.000,00$ e R $\$ 2.500,00$ ): Gama, Ceilândia e Samambaia. As RA com menor número de solicitações/reclamações são: Jardim Botânico no Grupo 1; SIA Grupo 2; Itapoã, Grupo 3; Fercal e Varjão, no Grupo 4 - Baixa Renda (abaixo de R\$2.500,00). Os dados apontam tendência para que as áreas com maior renda per capita no DF, com maior nível de escolaridade e, consequentemente, maior conhecimento da problemática da presença dos pombos apresentam maior número de registro de reclamações. É razoável inferir, ainda, que entre a população com maior escolaridade haja maior conhecimento dos canais de atendimento dos órgãos públicos.

A oferta de abrigo se caracteriza pela arquitetura moderna de edificações e monumentos, de linhas geométricas e semelhança com penhascos rochosos, presentes principalmente no centro das RA do DF, como também por residências que apresentam lacunas em telhados e casas de caixa d'água, todos servindo como fonte de proteção aos pombos da diversidade climática, para a instalação de ninhos (SANTOS, 2011).

A quantidade de alimento disponível nas cidades, seja pelo acúmulo oriundo das atividades humanas ou proveniente de oferta direta aos pombos, associada a pouca seletividade alimentar dessas aves aumenta a sobrevida desses animais. Assim, pombos que, pela seleção natural na busca de alimento poderiam morrer, acabam prolongando suas vidas, já que há alta concentração de alimento e menos disputa pela sua obtenção (NUNES, 2003).

$\mathrm{O}$ acesso à água é encontrado em abundância pelas cidades satélites do DF, em poças formadas pela chuva, ou em lavagens de carros e varandas, como também em resíduos plásticos que acumulam e mantém água à disposição das aves. Outros exemplos marcantes de oferta de água podem ser observados na capital (Brasília): a existência de espelhos de água nas edificações e espaços públicos como o Palácio do Planalto, Congresso Nacional e o Museu Nacional Honestino Guimarães; fontes de águas dançantes próximas à antiga Torre de Televisão; além do peculiar monumento dedicado à nidificação dos pombos e fonte de abrigo, conhecido popularmente como Pombal.

\section{Considerações finais}

Este estudo indicou que, em relação às solicitações/reclamações sobre animais sinantrópicos, pombos são considerados um fator incômodo pelos habitantes do DF. Dentre os possíveis motivos para esse fato se destacam o simbolismo dessas aves e o desconhecimento pela população sobre o manejo adequado. As ações de vigilância, principalmente as de educação em saúde, com orientação sobre o destino adequado dos resíduos e obstrução de acesso a abrigos, tornam-se limitadas frente à disponibilidade de alimentos, que representa um dos principais fatores no ambiente urbano para a proliferação dos pombos e ocorrência de doenças. Quanto menor a disponibilidade dos elementos essenciais para a permanência dos pombos - água, alimento, abrigo, acesso - próximo ao convívio humano, menor será sua população e os problemas em decorrência.

No DF, o tamanho da população e a distribuição de renda apresentaram diferença na distribuição do número de registros de solicitações/reclamações, que apontaram uma possível sazonalidade com aumento no período de inverno e início de primavera.

Conhecer a distribuição das reclamações sobre pombos é imprescindível para o implemento de ações visando a diminuir os prejuízos que essas aves carreiam. É necessário o conhecimento do real problema causado por essa espécie sinantrópica, das informações sobre as mudanças sazonais, locais de pouso e nidificação, oferta de alimentos, água e estruturas que facilitem a permanência dos pombos para elaboração de propostas de controle de abrigos com mecanismos físicos, bem como dificultar o acesso à água e alimentos. A observação da presença desses animais em áreas sem registro de reclamações também é aspecto interessante a ser observado. Todas essas informações são importantes para direcionar programas de saúde, definir medidas adequadas aos casos, conhecer as regiões mais vulneráveis ou regiões emergentes. O controle da populacional de pombos domésticos no meio urbano deve ser uma ação conjunta entre órgãos governamentais e a sociedade - que precisa de orientação e educação continuada.

Estudos continuados, com técnicas de zoogeografia em interface com Geografia da Saúde, constituiriam ferramentas importantes para ampliar o conhecimento acerca da distribuição dos pombos domésticos, nas áreas urbanas e rurais, do Distrito Federal.

As ações de educação em saúde são importantes no controle populacional de animais e são base para ações e políticas públicas para promoção do desenvolvimento saudável de homens, animais e ambiente, como uma só saúde. 


\section{Agradecimentos}

Os autores agradecem o incentivo do Programa Institucional de Iniciação Científica (2017) da Universidade de Brasília e o apoio do corpo técnico da Diretoria de Vigilância Ambiental (DIVAL/DF) no desenvolvimento deste trabalho.

\section{Referências}

ALI S. et al. Ecology of feral pigeon (Columba livia) in urban areas of Rawalpindi/ Islamabad, Pakistan. Pakistan Journal of Zoology, v.45, n.5, p. 1229-1234, 2013.

ALVES, M.T.G.; SOARES, J.F. Medidas de nível socioeconômico em pesquisas sociais: uma aplicação aos dados de uma pesquisa educacional. Opinião Pública, Campinas, v. 15, n. 1, p. 1-30, 2009.

BENCKE, G A. Pombos domésticos: Sugestões para o controle em Escolas Públicas Estaduais de Porto Alegre. Governo do Estado do Rio Grande do Sul, 2007.

Brasil. Ministério da Saúde. Secretaria de Vigilância em Saúde. Departamento de Vigilância das Doenças Transmissíveis.

Manual de vigilância, prevenção e controle de zoonoses: normas técnicas e operacionais [recurso eletrônico] / Ministério da Saúde, Secretaria de Vigilância em Saúde, Departamento de Vigilância das Doenças Transmissíveis. - Brasília: Ministério da Saúde, 2016.

CHIARENTIN, K. C. et al. Nível socioeconômico e grau de escolaridade: relação com as oportunidades para o desenvolvimento infantil. EFDeportes.com, Revista Digital. Buenos Aires, Año 17, n.167, 2012.

CLIMATEMPO. Mínima, máxima e precipitação em Brasília. Disponível em: https://www.climatempo.com.br/climatologia/61/ brasilia-df. Acesso em: 26 jul. 2017.

DISTRITO FEDERAL. Companhia de Planejamento do Distrito Federal - Codeplan. Pesquisa Distrital por Amostra de Domicilios (PDAD/DF), 2015. Disponível em http://www.codeplan.df.gov.br/ component/content/article/261-pesquisas-socioeconomicas/319pdad-2015.html. Acesso em: 4 mar. 2017.

FERMAN, L. M., PETER, H.U.; MONTALTI, D. A study of feral pigeon Columba livia var. in urban and suburban areas in the city of Jena, Germany. Arxius de Miscellània Zoològica, v. 8, p. 1-8, 2010.

GDF-Secretaria do Estado de Saúde do Distrito Federal, Diretoria de Vigilância Ambiental - DIVAL. Disponível em: http://www. saude.df.gov.br/sobre-a-secretaria/subsecretarias/617-diretoriade-vigilancia-ambiental-dival.html. Acesso em: 23 jun. 2017.
HAAG-WACKERNAGEL, D. Regulation of the street pigeon in Basel. Wildlife Society Bulletin, 23: 256-260, 1995.

HAKKINEN, I.; JOKINEN, M; TAST, J. The winter breeding of the feral pigeon Columba livia domestica at Tampere in 1972/1973. Ornis Fennica. 50: 83-88, 1973.

IBGE. Instituto Brasileiro de Geografia e Estatística, Estatísticas, 2016. Acesso em 2017 jul 8. Disponível em: http://downloads. ibge.gov.br/downloads_estatisticas.htm

MEZA, J.M. Las especies invasoras vertebradas. Revista Biocenosis, v.22, n.1-2, p. 3-12, 2009.

MONTENEGRO NETO, H; NUNES, V.F.P. A problemática dos pombos em áreas urbanas. Vetores \& Pragas, v.1, n.3, p.11-14, 1998.

MOUTINHO, F.F.B. et al. Distribuição espaço-temporal das reclamações sobre pombos (Columba livia doméstica) efetuadas ao centro de controle de zoonoses de Niterói, RJ (2009-2013). Hygeia, v.11, n.21, p.49-61, 2015.

NUNES, V.F.P. Pombos urbanos: o desafio de controle. Biológico, v.65, n.1/2, p. 89-92, 2003.

PAPINI, S. Vigilância em saúde ambiental: uma nova área da ecologia. 2 ${ }^{\mathrm{a}}$.ed. rev. e amp. São Paulo: Atheneu Editora, 2012.

SALVATO, M. A.; FERREIRA, P.C.G.; DUARTE, A.J.M. O impacto da escolaridade sobre a distribuição de renda. Estudos Econômicos (São Paulo), v. 40, n.4, p. 753-791, 2010.

SANTOS, I.O.C. Pombos no Distrito Federal: Problemas e Reflexões. Monografia [Conclusão de Curso de Medicina Veterinária] - Faculdade de Agronomia e Medicina Veterinária, Universidade de Brasília, DF. 59p. 2011.

SCHULLER, M. Pombos urbanos: um caso de saúde pública. Revista SBCC, v.29, p. 32-37, 2005.

SHERMAN, G.E. et al. Quantum GIS User Guide - Version 2.14.1. Disponível em: http:www.qgis.org/em/site/forusers/download.html. Acesso em: 15 jun. 2017. 